\title{
Employment Rights Disputes: what is the role of HR professionals?
}

Bernard Walker

University of Canterbury, Christchurch, New Zealand

R.T. Hamilton

University of Canterbury, Christchurch, New Zealand 


\title{
Employment Rights Disputes: what is the role of $\mathrm{HR}$ professionals?
}

\begin{abstract}
This study explores the role of human resource specialists in the handling of employee grievances. Most studies of HRM devolution have drawn only on the perceptions of managers and have neglected the area of grievances. The research highlights the employee experience of grievances under different levels of HRM devolution. The progression of fourteen grievance cases was investigated, accessing the full set of parties to each one. Data were gathered using a triangulated method involving seventy interviews, direct observation and written submissions. The findings suggest grievance handling is not readily accommodated within devolved HR structures. The role of HR staff in grievance processes can be ill-defined and show wide variation, causing problems for both line managers and employees. This can lead to negative outcomes and damage the credibility of the HR department. The insights from this study are intended to initiate debate concerning the potential roles of HR practitioners in grievance handling.
\end{abstract}

\section{Keywords}

Grievances, mediation, alternative dispute resolution (ADR), devolved HRM, New Zealand, HRM staff 


\section{Introduction}

This paper explores how employee grievances are handled under devolved HRM structures. Human resource management involves managing people within the employer-employee relationship. In recent decades, HR professionals have been seeking a more relevant and strategic role by devolving many operational HRM tasks to line managers (Whittaker and Marchington 2003) or outsourcing these functions (Delmonte and Sels 2008). Grievance-handling is an HRM activity that can be challenging and costly (Shulruf et al. 2009; Woodhams 2007). Even with well-trained staff and comprehensive human resource policies, grievances still occur and organisations need to minimise their negative consequences (Olson-Buchanan and Boswell 2002). However, the role of HR staff is often ill-defined when grievance handling is devolved to line managers. This paper suggests that the effective engagement of HR staff in grievance cases merits further investigation and debate.

\section{The literature}

In this paper, we work at the intersection of two literatures. The first is the devolution of operational HRM, facilitating the rise of strategic HRM; the second concerns employment rights disputes, commonly termed grievances.

The question of how HRM contributes to firm performance remains an ongoing area of inquiry. We are not concerned here with the performance impact of HRM. Instead, our work focuses on how devolved HRM is delivered from the seldom-heard perspective of the aggrieved employee (Edgar and Geare 2005, 361) in what Boselie et al. $(2005,73)$ refer to as the "exit phase" of the employment relationship. In adopting this focus, we can be accused of highlighting only the costs of HR devolution but in response we would assert that these costs are significant and may indeed compromise the credibility of HR staff (Teo and Rodwell 2007, 280).

Devolved HRM is delivered through line managers who have numerous operational responsibilities and are often less experienced in HR matters, particularly grievances. There have been many studies of this devolution process, most of which have asked either HR managers and/or line managers about the benefits and costs of these role changes. Despite the reservations in Osterman (1994), some studies continue to ask senior HR managers about the implications of their strategic role (e.g. Kulik and Perry 2008). Senior HR managers are reported as approving of the devolution of their operational role and they perceive that the effectiveness of people management has improved (Perry and Kulik 2008). 
Other studies garner the perceptions of HR managers and line managers regarding the emergence of strategic HRM (Conway and Monks 2010; Harris 2007; Teo and Rodwell 2007; Whittaker and Marchington 2003). These studies generally report the hesitation with which line managers have assumed operational HR responsibility and, when they have to act in an $\mathrm{HR}$ role, they remain least comfortable in dealing with major employee grievances (Conway and Monks 2010; Harris 2007; Teo and Rodwell 2007; Whittaker and Marchington 2003, 254). Through all of this, the HR managers regard the line managers as their clients (who need more HR training) and the line managers see HRM responsibilities as an added burden to their other full-time duties.

The second area is the extensive literature on employment rights disputes (Walker and Hamilton 2011). Research has largely focused on separate components of the grievance process, e.g. grievance initiation (Knight and Latreille 2000b; Lewin 1999; Lewin 2004) and employee motivation for grievance filing (Bacharach and Bamberger 2004; Lewin 2004; 2005; Olson-Buchanan and Boswell 2008). It is argued that having grievance processes can bring a range of benefits including resolving conflict, minimising worker discontent and reducing turnover. Employees also benefit through the protections offered, and being able to resolve disputes rather than having to exit (Boroff 1991; Freeman and Medoff 1985; Lewin 2005; Olson-Buchanan 1997).

Our work falls within the area of grievance processing, where research has demonstrated links between employees' perceptions of organisational justice and organisational measures such as job satisfaction, organisational commitment, withdrawal, and organisational citizenship behaviours (Colquitt et al. 2001). The perceived justice of grievance procedures is linked to a belief in overall workplace justice, and satisfaction with the union and management (Fryxell 1992; Fryxell and Gordon 1989). Usage of grievance procedures has also been associated with their perceived fairness (Bingham 2004; Colvin 2003; Petersen and Lewin 2000), with Blancero and Dyer (1996) highlighting the need for systems perceived as 'credible', 'accessible' and 'safe'. Several studies (see Lewin 1999) have found significant positive relationships between the presence of a grievance procedure, and organisational performance. The evidence suggests that fair and effective grievance procedures can positively influence a number of organisational measures which are highly relevant to operational and strategic HRM. Many areas remain under-researched, however, including the ongoing processes within disputes, and the role of HR staff within grievance processes (Lewin 2004; 2005). 


\section{Methodology}

We gained access to fourteen disputes which went to external mediation. These cases were 'ongoing' disputes, with parties still in an employment relationship, thus affording the greatest opportunity to learn about processes (Yin 2003). The fact that our cases were identified at the point of external mediation means that we are dealing with disputes that were not resolved internally. Gaining access to study grievance processes is difficult given the obvious sensitivities and confidentiality issues (Bingham 2007; Bingham and Chachere 1999; Lewin and Peterson 1999). The study followed the progression of specific disputes, accessing the full set of parties involved in each case, including employer, employee, union and legal representatives and mediators. Earlier studies have typically been limited by using aggregate groups or only a single party to a dispute (Knight and Latreille 2000a; Woodhams 2007). The cases were chosen on a basis of available access with mediation staff identifying new ongoing cases and then consent being sought from all parties involved in a case. Thus, case selection was shaped by the practicalities of access. All but one of the employees were experiencing their first formal grievance, and the majority had been with the employer for at least five years. Among the employing organisations, all but three had in-house HR services and the other cases used outsourced HR support. A summary of the cases is shown in Table 1.

The data came from three sources that triangulated each other: interviews, observations, and written documentation. Seventy audio-taped in-depth interviews were conducted with parties, their legal advisors and mediators. One researcher attended mediation sessions as an observer. Finally, sets of documents were made available, including premediation correspondence, submissions for mediation, and employers' internal dispute procedures. Data gathering occurred at multiple points and as close as possible to the actual events so as to minimise the risk of retrospective sense-making and attribution error. Data analysis followed Eisenhardt (1989), developing detailed analyses of each separate case for within-case analysis, followed by cross-case analysis which allowed the identification of overall paths for the mediation process. Separate decision-paths for each of the parties were developed to fully define the interactive dynamics involved. To confirm the preliminary codes, transcripts were entered into NVivo with constant comparison between the emergent constructs and the data leading to the final set of codes. 


\section{Resolution processes and dispute outcomes}

The outcomes from the disputes formed three patterns. The first comprised five cases where the employment relationship was terminated at mediation. A second group of six cases involved employees who remained briefly with their employer after mediation, but subsequently terminated their employment as a result of the dispute, a group typically not captured in grievance research. The third group is where employees continued their employment relationship on a long-term basis. Although all cases were situations where the parties were seeking to maintain or restore their employment relationship, only three achieved this.

The cases where employment was maintained were typically characterised by the distinctive manner in which HR staff were engaged. These organisations had previously experienced a number of disputes and now deployed their HR staff to be more directly involved in dispute resolution. In one, the national HR advisor was based at a corporate site but worked closely with local managers providing education, mentoring and direct early-involvement in issues. As matters arose, managers would refer these to the HR advisor who would coach and advise the managers, and where necessary work directly with both the employer and employee to assist in achieving resolution. The HR staff had also collaborated with the union to establish internal resolution procedures which were widely perceived as fair and effective. Conflict could be channelled through these forums using established protocols between the parties, avoiding the escalation associated with external forums and outside parties. Another form involved the organisation addressing employment disputes by situating their HR staff at local level so that they could function in a more proactive manner. This permitted the HR staff to be aware of issues as they first emerged. Intervention and prompt resolution could occur at an early stage before matters escalated and relationships deteriorated. Again, the role of HR staff included advising managers as well as more direct intervention to assist in resolution. Recurring issues such as alleged bullying or recurrent disputes involving a particular manager could also be identified and addressed. These forms represented more traditional examples of deploying HR staff, and although not handling every aspect of day-to-day HRM, they were closely involved in grievance handling. These are markedly different from the devolved HRM responsibilities that now become the focus of attention.

We develop two cases exemplifying devolved HRM; each has an in-house HR function but line management has primary responsibility for grievance handling. The first of 
these, RETAIL, led to termination of the employment relationship even though the parties had hoped mediation would restore this. The second, BLUCORP, is an example in which the employment relationship was preserved, not primarily as a result of the involvement of HR staff but rather through the involvement of a line manager. This case illustrates the conditions that are necessary for devolved grievance-handling to be effective; as will be seen, those conditions may not commonly be present in organisations. These serve as cases from which the greatest learning can occur regarding the dynamics associated with the deployment of HR staff (Eisenhardt and Graebner 2007; Yin 2003).

We set out the processes in RETAIL and follow this by a discussion of the dynamics and HRM issues involved. We then present BLUCORP and discuss how that case was handled differently leading to employment preservation.

\section{RETAIL: employment termination}

Stage 1 Employee has been with the organisation for 7 years. A new team manager (TM) targets the employee with personalised criticism and insults, despite good work performance. TM has a pattern of repeatedly bringing certain staff to tears, often criticising non-work-related issues. Employee initially takes no action but a series of job changes occur where the employee is placed in situations without sufficient staffing or resources and is set up to fail. Employee complains to the overall store managers (previous and current) several times.

Stage 2 Current store manager is new and finds it hard to judge employee's complaints; has confidence in TM and so does not really believe employee complaints.

Stage 3Employee finds dialogue with store manager is not effective and no other resolution options exist within the organisation. Although afraid of provoking management, increasing stress and health problems mean employee feels the need to take action and perceives that the only option is to engage an external representative.

Stage 4 Worksite meeting occurs between employee's representative and TM to discuss the problems. Store Manager is absent. Following the meeting, the Store Manager and TM perceive the employee's introduction of the representative as aggression which they need to defend against. 
Stage 5Employee experiences threatening comments from Store Manager, suggesting that management are ready for a fight and to "bring it on" as employee will be defeated. Colleagues warn that manager is looking to target employee; verbal attacks from TM continue. Employee's representative writes to employers proposing another meeting or mediation. Employee hopes that mediation will alert company's Corporate Office to TM's behaviour, prompting their involvement and resolving the problems.

Stage 6 Store Manager feels inexperienced in dealing with grievances so forwards matters to corporate HR. HR advisor enters: obtains Store Manager's synopsis of events; decides to attempt to maintain employment. Writes to representative choosing mediation.

\section{Stage $7 \quad$ Mediation}

Employee's representative is angered by Store Manager's denials and becomes aggressive, leading to heated exchanges. Employee is also angered by perceived lies told by Store Manager. Realises could not continue to work with this manager and relocation within the company is not feasible, so decides to leave the company.

Store Manager is surprised by what that has been occurring that he has been unaware of. HR advisor only now becomes aware of the full issues, including the interpersonal conflict and allegations concerning TM's behaviour. The intensity of the exchanges in mediation suggests that continuing employment is not realistic and so HR advisor agrees to an exit settlement.

The discussion of RETAIL will initially outline a set of common dynamics that were present across all cases, then move to of the specific dynamics of RETAIL and a group of similar cases.

Throughout this and similar cases, the employee's decisions centred upon two questions. The first was whether to initiate dispute action; this included making complaints within the organisation, enlisting third-party representation, and pursuing mediation. Second was the decision to either remain with the employer or exit the relationship. The employee was continuously assessing how s/he could influence the situation and satisfactorily resolve the problems. When one attempt, such as the direct personal action within the organisation, proved unsuccessful, the employee moved to another approach that held the prospect of 
greater influence, such as introducing a third party. These dynamics drove the progression of the dispute.

The employee's decision whether or not to remain in the employment relationship was influenced by increasing costs associated with her health and family relationships, coupled with decreasing trust in the employer. These costs grew to eventually outweigh the benefits of employment. Crucially, as the dispute progressed, the employee came to realise that, despite numerous attempts, she was unable to influence the situation. In spite of limited labour market options and other factors deterring the employee, it seemed that the only realistic option available was to end employment. The RETAIL employee recounted the reduction in anxiety and physical symptoms that occurred after the dispute ended:

I don't have rashes all over me anymore. I'm nowhere near as grumpy, I don't get headaches, my asthma's much better... I've got two children and I was just an absolute ${ }^{* * *}$ to them. (Employee, RETAIL)

In contrast, for the employer, differing personnel handled the dispute at various stages. Initially, this was the on-site line manager, with HR personnel (and in some cases, senior managers) becoming involved later. The focus of decision making was however similar to that of the employee, centring on perceptions of the costs and benefits of maintaining the employment relationship. While the employee focused on more personal consequences, the employer's assessment was based on business-related considerations; their dependence on this particular employee, the influence of the employee's ongoing presence, and the exit price attached to a termination.

RETAIL exemplifies a more specific set of dynamics that occurred in similar cases. A major turning point in the dispute sequence was the introduction of external third-party representation. This came about when the employee perceived that there were no viable resolution avenues within the organisation, believing that the official organisational procedures were unlikely to satisfactorily resolve the problems. The employee recounted how the increasing negative effects of the dispute on her well-being, coupled with the absence of viable internal procedures, meant that she felt she had no option but to seek external assistance:

She would have made my life absolute hell - I mean it was bad enough, I didn't want it to be any worse.

I didn't want to bring anybody like [advocate] in - I wanted to try and keep some kind of peace - I mean to bring [advocate] in was a last resort. I knew that that was just putting a real cat amongst the pigeons basically. (Employee, RETAIL) 
This introduction of an external party formed the greatest source of escalation, and brought a marked change in the dynamics. Dialogue and direct communication between the employer and the employee ceased and their relationship became more acrimonious. The parties became more distant from each other and this gave rise to misinterpretations concerning the other party's intentions, with each side tending to attribute negative intentions to the other party's actions. When the RETAIL employee brought in an external representative, the employers perceived this as an aggressive move and so commenced their own increasingly defensive actions, bringing in their own representation and support from Corporate Office to counter the perceived attack. Matters were further compounded by the shift to formal written correspondence, with direct discussions between the employee and management ceasing. These processes in RETAIL and similar cases comprised a sequence of retaliatory interactions and escalation, leading to a classic conflict spiral (Pruitt and Kim 2004). Once such escalation occurred, the dispute typically proceeded to external mediation and termination of the relationship.

The role of HR staff in RETAIL was noticeably limited, only becoming directly involved in the very final stage(s), with last-minute attempts to initiate dialogue with the employee and avert a departure. Prior to mediation, the HR person only had time to gather one side of events, that of the line manager but not the employee:

the store manager, I would ring up whoever that was, get an understanding in their words what the situation is... Given that it's gone to mediation I won't get in contact with the applicant because it's already far past that (HR Advisor, RETAIL)

At this late stage, the employer-employee relationship had significantly deteriorated. The disputed issue(s) had become transformed into a legal challenge and the HR practitioner's own role required her to focus on primarily defending the organisation. The dynamics of the mediation setting, with parties intent on defending their positions against legal challenges, precluded restorative efforts.

The RETAIL employee, however, desired the involvement of HR staff. Part of the employee's motivation for initiating dispute action was the hope that this would prompt the involvement of corporate staff, particularly HR, as they were trusted and perceived as potentially bringing a more detached perspective and conflict-handling skills. The employee hoped that HR staff could open up dialogue and possibly resolve matters within the organisation; a hope shared by employees across a number of cases. This rarely eventuated though. Instead, the company typically responded to the employee's action by ceasing dialogue and becoming more entrenched. 
In these situations, HR staff served as "short-term defenders", entering only in the final stages, focusing on countering employee claims and defending the organisation against legal threat. A critical opportunity to resolve disputes existed during the early stages; at this time, the matter could still be dealt with within the organisation while the employer-employee relationship was still intact. Once this opportunity was lost and external agents became involved however, the chances of resolution were low. HR staff only entered after this point, by which time the dispute had escalated with little chance of restoring the relationship.

The processes outlined in RETAIL were closely illustrative of seven of the cases studied. In addition, other cases were variants of this pattern; for example, where an employee did not use an external representative nonetheless the same type of critical juncture occurred with the employee's move to utilise external assistance through mediation.

\section{BLUCORP: employment preserved}

BLUCORP profiles an alternative dispute-sequence that was led to successful resolution and addressed the interests of all parties.

Stage 1 Employee applies for a vacant position but application is not successful; instead a person from an agency is appointed. Employee initially discusses matter with the branch manager who made the appointment decision and also contacts union who have a close, ongoing involvement in the workplace.

Stage 2 The Branch Manager initially deals with questions from the employee but when the matter is not resolved forwards the issue to the Area Manager and corporate office.

Stage 3The corporate HR team propose that, technically, the company's actions are defensible and the appointment decision should be upheld. At the local level, Area Manager enters into ongoing weekly discussions with employee, exploring options for resolution. Employee feels this preserves the relationship and gets around problems with immediate manager.

Stage 4 Corporate HR staff propose contesting the issue as a matter of principle, framing it as legal question concerning the organisation's ability to make appointments. Although Corporate HR specialists provide technical advice, the Area Manager has authority to make decisions. 
Stage 5Union propose mediation; at corporate level, management and union are ready and willing to legally contest their positions.

Stage 6Area Manager attempts to defer the need for formal proceedings, believing these will only make parties more entrenched. Instead, he continues dialogue with the employee, seeking to address the employee's interests while still acknowledging legal issues. Similar discussions occur with the union as part of the Area Manager's established working relationship with local organisers.

Stage 7Mediation: As no agreement had been reached at the corporate level, union officials continue with planned mediation as a means to progress the apparent stalemate between the parties. Area Manager determines the approach of the employer side, instructing the HR manager in his preference for non-adversarial discussions and low-level problem solving resolution. Branch Manager attends with Area Manager. Both sides agree to explore options for addressing the employee's needs and offering employment. Area Manager initiates and supports the process, then employee works with colleagues and managers to implement this. A plan is mutually agreed which accommodates colleagues' preferences for changes to their hours of work, preserves the local manager's status, and gives the employee full-time work.

In BLUCORP, a senior line manager (Area Manager) engaged continuously with the employee from very early stages through to post-mediation resolution. The Area Manager communicated directly with the employee and explored both sides, obtaining the employee's and line manager's accounts of events, and discovering that the immediate manager may be part of the problem. This is different from cases such as RETAIL where there is a chasm, with virtually no direct contact between the employee and senior management or HR staff. In those cases, entering late in the process, corporate HR staff rely solely upon the local manager's accounts without contacting the employee to ascertain how the relationship is working from both sides. This creates a significant blind spot for HR staff who are unaware of the major problems occurring, until mediation. By that time, it is too late to save the relationship.

In both cases, the employee introduced a third party. With RETAIL, this was an external representative who had no prior relationship with the company's managers. For the RETAIL managers, the entry of such a representative transformed the issue into a legal challenge, alleging that they have breached their contractual or legal obligations. This significantly escalated the dispute and moved the parties further apart. In BLUCORP however, the third 
party is the union. Over a period of time, the Area Manager had established a working relationship with the union representatives which allowed them to jointly address and resolve issues with minimal escalation.

The Area Manager's role in BLUCORP was that of an active resolution agent, engaging continuously with the parties and seeking to resolve the dispute by acknowledging the interests of both parties. Addressing both local and corporate levels, the manager gained detailed awareness of the issues. The manager had a strong focus on maintaining relationships, deliberately seeking personal contact and ongoing dialogue. From his business experience and his out-of-work involvement in coaching and development, he had considerable experience in resolving disputes, choosing to adopt a problem solving, rather than contending or confrontational approach (Pruitt and Kim 2004), thus averting the destructive dynamic of escalation and relationship decline. As a consequence, the employee did not experience ever-increasing costs, still trusted a member of management, and remained hopeful of resolving the issues.

\section{Discussion}

These organisations varied in their capacity for within-company resolution. While this may reflect the sampling which drew upon cases reaching mediation, other reports suggest that they may be typical of a widespread lack of successful dispute resolution at company level (Department of Labour 2000; 2003). Conversely, however, when disputes are resolved prior to mediation, this tends to be associated with the active involvement of HR staff (Woodhams, 2007).

In both the RETAIL and BLUCORP scenarios, the direct involvement of HR staff was limited. The first-line managers (to whom the employees directly reported) were not trained or equipped for this role, did not receive substantial coaching or support, and lacked the time to deal with the issues. The functional relationship between HR and line-staff was confined to providing technical advice and/or entering late as short-term defenders. Crucially, the immediate managers were themselves part of the problem. The BLUCORP Area Manager criticised the HR section for focusing on legal and technical matters but failing to directly assist in resolving disputes:

People Capital Consultants in [city] ... are very strong on process and they seldom advise us they articulate what the managerial processes are. I don't find it a very useful role frankly...

I'd call them risk managers actually, compliance risk-managers. 
These findings challenge the effectiveness of devolving HR activities and the diminished role of HR staff in employee disputes. Organisational protocols need to provide staff who can competently intervene in the early stages of a dispute while the critical opportunities for resolution exist. The absence of such low-level resolution is a catalyst for the introduction of external third parties, escalation, and the eventual demise of the relationship. Unlike the situations with active HR involvement and preserved relationships, the line managers in these devolved cases were left to deal with complex issues with limited assistance. Similarly, the aggrieved employees wanted the involvement of HR professionals but found those staff had been moved away to a more 'strategic' location within the firm. In the absence of skilled early intervention, the disputes escalated.

The grievance literature places considerable emphasis on the need for effective withincompany dispute resolution systems that are 'accessible' to all staff ; 'safe', in not provoking retribution; and 'credible' in objectively resolving problems (Blancero and Dyer 1996; Harlos 2001). These matters hinge largely on the perceptions of the individuals handling disputes. While the organisations studied claimed to have resolution procedures in compliance with legislative requirements, in practice, those procedures typically expected employees, unable to resolve an issue with their immediate manager, to go to another manager. Very few employees used the procedures since, in contrast to the positive way in which employees perceived HR staff, line-managers were instead viewed as lacking partiality and/or the ability to deal with disputes:

The situation is that the procedure, if you like to call it that, would be that if the team member's not happy with the store manager's answer then they've got an area manager that they can [go to] - so you'd go to your next line manager. (HR Advisor, RETAIL)

'Cause the only other people that you can sort of go to are all managers and they are all very, very cliquey. (Employee, RETAIL)

In some cases, the organisational structure meant that it was not possible for HR staff take a greater role. RETAIL had only two corporate-based HR staff dealing with 60 worksites and several thousand employees across a wide geographical area. HR staff are responsible for legislative requirements which may also contribute to the tendency for them to function as short-term defenders or compliance risk-managers. In other situations, HR staff did have the ability to become involved but deliberately chose not to, believing it better not to intervene in a matter between the employee and their immediate manager so as to maintain boundaries and avoid potentially undermining local managers. This meant that HR staff had to trust that the manager-employee relationship was working well, whereas the reality in these cases was quite the opposite, leaving the HR staff oblivious to the problems. 
Cases such as BLUCORP demonstrate, however, that the balance between involvement and respecting local managers' authority can be achieved while actively working towards conflict resolution:

the challenge there is if I become an open door for the manager's staff I've got to be careful about the manager's position in this. (Area Manager, BLUCORP)

The BLUCORP scenario illustrates that there is potential for successful resolution when there is a competent line manager providing direct, early intervention, and continuing this throughout a dispute. This can positively influence events and restore or maintain the employment relationship. However, a range of conditions are necessary. The significant within-company resolution that occurred was not so much due to standardised organisational systems but rather was dependent on a particular individual and his personal practices. He was a very skilled and confident individual who had both the time, and the desire, to become involved in handling disputes. The person held a key role within the organisation with the authority to intervene in disputes, and had ultimate decision-making authority, even over-ruling the advice from HR staff. At the same time, the person was able to maintain relationships with other line-management staff, for example, choosing to involve them in the resolution process rather than imposing solutions, and gaining their ownership of decisions. This is a rather unique cluster of conditions that were not present in the other cases in the study, and there are indications that, more generally, these conditions may not commonly be present in organisations (Department of Labour 2000; 2003; Woodhams 2007). In sum, devolved HRM can work effectively in some situations but a distinctive set of conditions are necessary for this to occur in the grievance arena.

\section{Conclusions}

The effectiveness of HR involvement in employment disputes has been recognised (Woodhams 2007) and remains valued by line managers and employees. In spite of this, devolved models of HRM bring considerably reduced levels of direct HR engagement. In cases such as RETAIL, the HR section was essentially disengaged until it was too late to salvage the relationships. The BLUCORP scenario illustrates the potential that can exist for resolving disputes using within-organisation means. This outcome was not due to wellestablished HR procedures within the organisation but rather the fortuitous presence of a skilled line-manager.

The clear distinction between cases with more traditional, active HR involvement and relationship preservation, compared to those with lack of engagement and consequent 
relationship decline, suggests that devolving HR responsibilities in the area of employee disputes may adversely affect outcomes. Devolution may mean giving tasks to managers who have neither the skills, nor time, to handle issues such as disputes. The necessary coaching and support may also be absent. While classic texts refer to the role of managers as mediators and negotiators (Lax and Sebenius 1986; Tjosvold and Su 2006), in reality such approaches are hampered by the limited skills of line-managers. Moreover, the line manager may themselves be a part of the dispute. Employee disputes represent a critical test of devolved HRM. Successful resolution of disputes may require the involvement of HR staff with adequate resourcing, direct involvement with staff, and an awareness of day-today operational and relational issues. The present study sought to explore in detail the dynamics associated with dispute resolution. However, it does not purport to assess the prevalence of those behaviours across wider populations. The present findings, combined with the information from other broader surveys, do point to the possibility that the absence of HRM staff may create sub-optimal dispute handling; effective handling may require the early involvement of HRM specialists. Such a role has had little explicit recognition in the literature regarding HRM functions.

While organisations may seek to improve performance through focusing on strategic HRM and devolving day-to-day duties, this may have created a vacuum of capability at the crucial level of handling employee issues. Line managers and those in strategic HR roles are both inclined to place grievances in the 'too hard' basket. Given the links between effective grievance handling and a number of critical organisational measures, including firm-level performance, such inadequacies in grievance handling may adversely affect organisational outcomes. Furthermore, failures in handling day-to-day issues may also negatively affect the quality of the strategic contribution of HRM (Harris 2007; 36), and this may be reflected in the ongoing decline in managers' perception of the value and influence of HR departments (Roffey Park 2011) . In light of the costs borne by the employee and the organisation, it could be argued that grievance handling is of strategic importance and should remain the responsibility of a senior HR manager.

Organisations which have devolved HRM will, however, resist suggestions of reintroducing specialists at local level, citing the immediate costs of additional HR staffing. So the question becomes what kind of strategies for grievance handling are likely to be cost-effective in these situations? The North American pattern of introducing an 'ombuds' for handling disputes, a person separate from both HR staff and line management, may only be practical in the very largest organisations. For other devolved situations, there is still an evident need to shift the focus of HR staff from technical advice and risk management to the tasks of 
designing effective grievance systems, as well as genuinely training and supporting line managers. The line manager's role also needs to be reworked to provide sufficient time for handling grievances. Paradoxically, while organisations believe that their HR and line staff are already achieving these goals, it seems that the reality may be somewhat different. Even if these immediate aspects are addressed, other more fundamental issues remain unanswered. Line managers who have been trained in grievance handling may still prefer that HR staff handle major cases, despite the fact that HR staff no longer consider this part of their role. Another significant challenge occurs with the dilemma of handling situations where the line manager themselves may be the cause of problems in the supervisoremployee relationship. Similarly, procedures offering employees recourse to other line managers for dispute handling may be of little value until employees come to trust line managers and view them being as impartial and competent in conflict handling. These types of matters may prove difficult to address in full.

The questions of how and when HR staff are engaged in dispute handling are issues that merit further debate. Those who make these decisions need to be cognisant of the costs that are incurred when organisational designs fail to deliver specialist HRM services when and where these are needed.

\section{References}

Bacharach S and Bamberger P (2004) The power of labor to grieve: the impact of the workplace, labor market, and power-dependence on employee grievance filing. Industrial and Labor Relations Review 57(4): 518-539.

Bingham LB (2004) Employment dispute resolution: the case for mediation. Conflict Resolution Quarterly 22(1-2): 145-174.

Bingham LB (2007) Evaluation Dispute Resolution Programs: Traps for the Unwary. Labor and Employment Relations Association, Proceedings of the 59th Annual Meeting Chicago, Labor and Employment Relations Association.

Bingham LB and Chachere DR (1999) Dispute resolution in employment: the need for research. In: Eaton AE and Keefe JH. Employment Dispute Resolution and Worker Rights in the Changing Workplace. Champaign, Illinois, Industrial Relations Research Association: 95-136.

Blancero D and Dyer L (1996) Due process for non-union employees: the influence of system characteristics on fairness perceptions. Human Resource Management 35(3): 343-359. 
Boroff KE (1991) Measuring the perceptions of the effectiveness of a workplace complaints procedure. Advances in Industrial and Labor Relations 5: 207-233.

Boselie P, Dietz G and Boon C (2005) Commonalities and contradictions in HRM and performance research. Human Resource Management Journal 15(3): 67-94.

Colquitt JA, Conlon DE, Wesson MJ, Porter COLH and Ng KY (2001) Justice at the millenium: a meta-analytic review of 25 years of organizational justice research. Journal of Applied Psychology 86(3): 425-445.

Colvin AJS (2003) The dual transformation of workplace dispute resolution. Industrial Relations 42(4): 712-735.

Conway E and Monks K (2010) The devolution of HRM to middle managers in the Irish health service. Personnel Review 39(3): 361-374.

Delmonte J and Sels L (2008) HR outsourcing: threat or opportunity? Personnel Review 37(5): 543-563.

Department of Labour (2000) Survey of employment disputes and disputes resolution. Wellington NZ, Department of Labour - Employment Relations Service and AC Nielsen.

Department of Labour (2003) Evaluation of the Short-Term Impacts of the Employment Relations Act 2000, Department of Labour, NZ

Edgar F and Geare AJ (2005) Employee voice on human resource management. Asia Pacific Journal of Human Resources 43(3): 361-380.

Eisenhardt KM (1989) Building Theories from Case Study Research. The Academy of Management Review 14(4): 532-550.

Eisenhardt KM and Graebner ME (2007) Theory Building from Cases: Opportunities and Challenges. Academy of Management Journal 50(1): 25-32.

Freeman RB and Medoff JL (1985) What do unions do? New York: Basic Books.

Fryxell GE (1992) Perceptions of justice afforded by formal grievance systems as predictors of belief in a just workplace. Journal of Business Ethics 11(8): 635-647.

Fryxell GE and Gordon ME (1989) Workplace justice and job satisfaction as predictors of satisfaction with union and management. Academy of Management Journal 32(4): 851-866.

Harlos KP (2001) When organizational voice systems fail: more on the deaf ear syndrome and frustration effects. Journal of Applied Behavioral Science 37(3): 324-342.

Harris L (2007) The changing nature of the HR function in UK local government and its role as "employee champion". Employee Relations 30(1): 34-47. 
Knight KG and Latreille PL (2000a) Discipline, dismissals and complaints to Employment Tribunals. British Journal of Industrial Relations 38(4): 533-555.

Knight KG and Latreille PL (2000b) How far do cases go? Resolution in industrial tribunal applications. The Manchester School 68(6): 723 - 744.

Kulik C and Perry E (2008) When less is more: the effect of devolution on HR's strategic role and construed image. Human Resource Management 47(3): 541-558.

Lax DA and Sebenius JK (1986) The Manager as Negotiator. New York: The Free Press.

Lewin D (1999) Theoretical and empirical research on the grievance procedure and arbitration: a critical review. In: Eaton AE and O'Keefe JH. Employment Dispute Resolution and Worker Rights in the Changing Workplace Champaign, Illinois, Industrial Relations Research Association: 187-218.

Lewin D (2004) Dispute resolution in the non-union organization: key empirical findings. In: Sherwyn D and Estreicher S. Alternative Dispute Resolution in the Employment Arena: Proceedings of New York University Annual Conference Series. New York, Kluwer: 379-403.

Lewin D (2005) Unionism and employment conflict resolution: rethinking collective voice and its consequences. Journal of Labor Research XXVI(2): 209-239.

Lewin D and Peterson RB (1999) Behavioral outcomes of grievance activity. Industrial Relations 38(4): 554-576.

Olson-Buchanan JB (1997) To grieve or not to grieve: factors relating to voicing discontent in an organizational simulation. The International Journal of Conflict Management 8(2): 132-147.

Olson-Buchanan JB and Boswell WR (2002) The role of employee loyalty and formality in voicing discontent. Journal of Applied Psychology 87(6): 1167-1174.

Olson-Buchanan JB and Boswell WR (2008) An integrative model of experiencing and responding to mistreatment at work. academy of Management Review 33(1): 76-96.

Osterman P (1994) How common is workplace transformation and who adopts it? Industrial and Labor Relations Review 47(2): 173-188.

Perry E and Kulik C (2008) The devolution of HR to the line: Implications for perceptions of people management effectiveness. International Journal of Human Resource Management 19(2): 262-273.

Petersen RB and Lewin D (2000) Research on unionised grievance procedures: management issues and recommendations. Human Resource Management 39(4): 395-406.

Pruitt DG and Kim SH (2004) Social conflict: escalation, stalemate and settlement. Boston: McGraw-Hill.

Roffey Park (2011) Management Agenda Report 2011. West Sussex 
Shulruf B, Woodhams B, Howard C, Roopali J and Yee B (2009) 'Grievance gravy train picking up speed': myths and reality around employment disputes in New Zealand. Journal of Industrial Relations 51(2): 245-261.

Teo S and Rodwell J (2007) To be strategic in the new public sector, HR must remember its operational activities. Human Resource Management 46(2): 265-284.

Tjosvold D and Su F (2006) Manager as Mediator: Developing a Conflict-Positive Organization. In: Herrman MS. The Blackwell Handbook of Mediation. Malden, USA, WileyBlackwell: 344-354.

Walker B and Hamilton RT (2011) Employee-employer grievances: a review. International Journal of Management Reviews 13(1): 40-58.

Whittaker S and Marchington M (2003) Devolving HR responsibility to the line: threat, opportunity or partnership? Employee Relations 25(3): 245-261.

Woodhams B (2007) Employment Relationship Problems: Costs, Benefits and Choices, August 2007. Wellington, Department of Labour.

Yin RK (2003) Case Study Research: Design and Methods 3e: Thousand Oaks, Calif. : Sage Publications. 
Table 1: Summary of the companies involved

\begin{tabular}{|c|c|c|c|c|}
\hline Case & Private / Public Sector & Industry & $\begin{array}{c}\text { Organisation } \\
\text { Total size }\end{array}$ & $\begin{array}{c}\text { Local } \\
\text { unit } \\
\text { size }\end{array}$ \\
\hline ALPHA & Private & Security / protection & 24 & 24 \\
\hline TECHS & Private & Electronics & 285 & 28 \\
\hline GAMMA & Private & Service / hospitality & 550 & 550 \\
\hline REDCORP & Private & Banking & 6000 & 9 \\
\hline RETAIL & Private & Retail & 3500 & 70 \\
\hline NEWS & Private & Media & 100 & 100 \\
\hline WASTE & $\begin{array}{c}\text { Public-Owned } \\
\text { Trading }\end{array}$ & Waste & 150 & 150 \\
\hline ROAD & Private & Construction & 3000 & 400 \\
\hline CORG - B & Public & Law and legal services & 1,817 & 34 \\
\hline MOVERS & Private & Removals & 240 & 35 \\
\hline TERMINUS & $\begin{array}{c}\text { Public-Owned } \\
\text { Trading }\end{array}$ & Transport / tourism & 175 & 175 \\
\hline CORG- A & Public & Law and legal services & 1,817 & 11 \\
\hline BLUCORP & Private & Banking & 2243 & 15 \\
\hline FLEET & Public & Emergency services & 2100 & 160 \\
\hline
\end{tabular}

